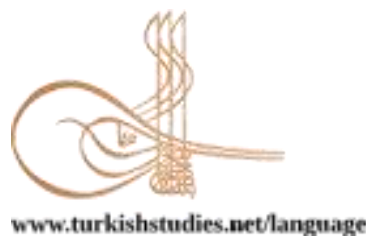

www.turkishstudies.net/language

\section{Turkish Studies - Language and Literature}

\author{
eISSN: 2667-5641
}

Research Article / Araştırma Makalesi

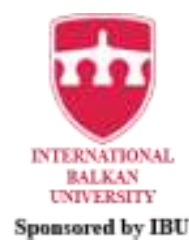

Sponsered by IBU

\title{
Post-editör mü Yoksa Son-biçimleyici mi?
}

\author{
Post-editor or Son-biçimleyici?
}

\author{
Burcu Türkmen*
}

\begin{abstract}
Translation Studies has proven its existence as an independent scientific field and the existence of interdisciplinary fields of study which belong to it. It is inevitable that Translation Studies, which has a wide interdisciplinary field of study, has a constantly developing terminology. Post-editors, which have been among the computer-assisted translation tools and editing programs for many years, can work-integrated and/or independently from neural machine translation programs. In this study, it has been determined that the concept called as post-editor is not included in the Turkish Translation Studies terminology, and does not have a constant usage as a term in the related literature review. In this context, it has been observed that the posteditors are called in general as editing after the machine translation, or the word post-edit, which is often English equivalent, is used exactly. The post-editors should not be considered only in connection with machine translation, it is suggested that the name be used as post-editor, as it is software that helps editors, publishers, content creators, translators, students, researchers in the production of creating the qualified texts. This study has been carried out to include the "son-biçimleyici" in Turkish Translation Studies terminology as a term, which is beneficial during the translation practices and in translation education in current research and the term suggestions for post-editors, post-edit and post-editing words into Turkish are given. Within the scope of the research, the importance of term production/derivation in a language was emphasized and a proposal was made for the Turkish equivalent of the concept, which is frequently referred to as post-editor in translation studies.
\end{abstract}

Structured Abstract: The Translation Studies, which continues to improve day by day, interacts with many different disciplines by putting across the new concepts and the terms. That's all that matters how the concepts and/or the objects that our society has just gained in the Turkish language. At certain times, the localization of the technological devices, programs, software, and even our mobile devices we use today are being transferred from different languages without a Turkish equivalent name. Such kinds of word usages are of course made within a certain scientific framework. It is inevitable that Translation Studies, which has a wide interdisciplinary field of study, has a constantly developing terminology. Post-editors, which have been among the computer-assisted translation tools and editing programs for many years, can work-integrated and/or independently from neural machine translation programs. In this study, it has been determined that the concept called as post-editor is not included in the Turkish Translation Studies terminology, and does not have a constant usage as a term in the related literature review.

\footnotetext{
* Öğr. Gör. Dr, Zonguldak Bülent Ecevit Üniversitesi, Çaycuma Meslek Yüksekokulu, Yabancı Diller ve Kültürler Bölümü, Uygulamalı İngilizce ve Çevirmenlik Programı

Dr. Lecturer, Zonguldak Bulent Ecevit University, Vocational School Applied English and Translation

ORCiD 0000-0001-5380-0480

burcuturkmen@beun.edu.tr

Cite as/ Atıf: Türkmen, B. (2020). Post-editör mü yoksa son-biçimleyici mi?. Turkish Studies - Language, 15(2), 867-

874. https://dx.doi.org/10.29228/TurkishStudies.43321

Received/Geliş: 03 May/Mayıs 2020

Accepted/Kabul: 20 June/Haziran 2020

Copyright $\odot$ INTAC LTD, Turkey

Checked by plagiarism software

Published/Yaym: 27 June/Haziran 2020

CC BY-NC 4.0
} 
The strategies, which may have particular influences on creating a term in the target language and new word acquisition, are accepted as the strategies used in the inter-language translation process. As a result of the literature review carried out within the scope of the current study, it was observed that the word posteditor is used in Turkish sources exactly with the same spelling. The post-editor term is generally used for the meaning of the correction after the machine translation with an explanation. Therefore, before the suggestion of the "son-biçimleyici" Turkish word and other related words and uses such as son-biçimleme, sonbiçimleyen, certain studies related to post-editors in Turkish are analyzed and evaluated within the scope of this study. Then, the word suggestions and their meanings are given in the conclusion of the study.

The post-editors are used to find spelling and wording errors on the texts prepared in the target languages, often in English, after translations or without translation. In addition to these features, the posteditors can make corrections such as semantic corrections, special uses, conjunctions, preposition usages, and capitalization. In this context, the aim of this research is to make suggestions for the Turkish equivalence of post-editor as a term, which is a correction tool that has been actively used by translation researchers, translators, translation students, who have been in the translation-oriented technology products classification for years.

This research has been carried out to include the "son-biçimleyici" in Turkish Translation Studies terminology as a term, which would contribute during the translation practices and in translation education in current research and the term (name) suggestions for post-editors into Turkish are given. The data obtained as a result of the literature research were gathered and compared, and analyzed and evaluated through the descriptive analysis method within the scope of the current research. In this way, a kind of situation analysis was made and a proposal has been made to include the "son-biçimleyici" presented in this study among the translation terms. Research questions are as follows: How does the concept of post-editor take place in Turkish Translation Studies and research? Why are terms important for a language? What are the Turkish term equivalent suggestions for post-editor and other related words such as post-edit and post-editing? To create high quality and proper text in the target language, post-editors are not only used in or after machine translation with the purpose of checking spelling, correct wording, punctuation, preposition and conjunction usages and etc. It should not be ignored that the post-editors are not only used as integrated into machine translation software and programs but also as independent from them. In this context, post-editors should not be considered only in connection with machine translation, it is suggested that the name be used as post-editor, as it is software that helps editors, publishers, content creators, translators, students, researchers in the production of creating the qualified texts. Using the "son-biçimleyici" in Turkish rather than the post-editing or the editing after the machine translation is thought to contributive to the Turkish language for determining the proper meaning.

Within the scope of future studies about post-editors, studies comparing different post-editors' features in machine translation programs can be analyzed under the translation quality. A comparative study can be conducted on how different independent post-editors correct the same text. Comparative studies can be carried out only by checking the same text both on a spellchecker and on an independent post-editor. Besides, it is recommended to conduct comparative studies on which the data quality of a single post-editor with different text types can be obtained.

Keywords: Translation Studies, post-editing, term, terminology, editing.

Öz: Çeviribilim, bağımsız bir bilimsel alan olarak kendi varlığını ve müdahil olduğu disiplinler arası çalışma alanlarının varlığını kanıtlamıştır. Geniş bir disiplinler arası çalışma alanına sahip olan çeviribilimin sürekli gelişmekte olan bir terminolojiye sahip olması kaçınılmazdır. Bilgisayar destekli çeviri araçları ve editörlük/düzeltmenlik programları arasında uzun yıllardır yerini alan son-biçimleyiciler (post-editor) nöral makine çevirisi programlarına bütünleşik ve/veya bu programlardan bağımsız bir şekilde çalışabilmektedir. Mevcut çalışmada son-biçimleyiciler olarak adlandırılan kavramın Türkçe çeviribilim terminolojisinde yer almadığı, ilgili literatür taramasında terim karşılığı olarak sabit bir kullanımının olmadığı tespit edilmiştir. Bu bağlamda, son-biçimleyiciler için genel olarak makine çevirisi sonrası düzeltme şeklinde açıklama yapıldı̆̆ ya da sıklıkla İngilizce karşılığı olan post-edit kelimesinin aynen kullanıldığ1 görülmüştür. Son-biçimleyiciler sadece makine çevirisi ile bağlantılı olarak düşünülmemelidir. Bu programlar editörlere, yayıncılara, içerik yaratıcılarına, çevirmenlere, öğrencilere, araştırmacıların nitelikli metin üretimine yardımcı olan bir yazılım olduğu için adının son-biçimleyici olarak kullanılması önerilmektedir. Bu çalışma, çeviri pratiği süresince

Turkish Studies - Language, 15(2) 
fayda sağlayan ve güncel araştırmalarda çeviri eğitiminde yer almasının gerekliliği savunulan sonbiçimleyicilerin Türkçe çeviribilim terminolojisinde terim karşılığı olarak yer alması için yürütülmüş ve sonbiçimleme yapmak, son-biçimleme ve son-biçimleyen/son-biçimleyici sözcükleri için terim önerileri verilmiştir. Bu araştırma kapsamında, bir dilde terim üretiminin/türetiminin önemi vurgulanmış ve özellikle çeviribilim alanında sıkça post-editör olarak anılan kavramının Türkçede kullanılan karşılığı için öneride bulunulmuştur.

Anahtar Kelimeler: Çeviribilim, son-biçimleme, terim, terminoloji, düzelti.

\section{Giriş}

Tarihi yüzyıllar öncesine dayanan çeviri kavramının önceleri göstergeler arası daha sonra diller ve kültürler arası köprüler kuran, anlaşılmayanları anlaşılır kılan disiplinlerarası bir alan olarak tanımlandığı bilinmektedir. Antik Yunan döneminden itibaren 17. yüzyıla kadar süren dönemde etkileşim halinde olan toplumlar arasında siyasi, ticari, edebi, psikoloji ve askeri bağlar nedeniyle kullanılan çevirinin 17.yy- 20.yy. arasındaki süreçte kendi çalışma alanlarına ve kuramsal yaklaşımlara sahip olan multidisipliner bir bilim dalı halini aldığı aşikârdır.

Araştırmaya dayalı ve kuramsal bir bilim dalı olmasının yanı sıra uygulama ve eğitim alanında da çeviribilim günümüz teknolojisinin de desteğini alarak sürekli bir şekilde ilerleme kaydetmektedir. Teknoloji denilince ilk akla gelen nesnelerin, bilgisayarların, İkinci Dünya Savaşı döneminde iletişim amacıyla kullanılıp kullanılmayacağı tartışılmaya başlanmıştır. Bahsi geçen tartışmalar o dönemin SSCB ve ABD arasındaki uzay yarışları başlayana dek etkili bir ilerleme sağlayamamıştır. Teknolojisinin çeviriyle ilgili ayağına bakıldığındaysa, 1950'li yıllarda Rusçaİngilizce dil çifti arasında sınırlı bir sözcük dağarcı̆̆ını çevirebilecek bir makine üretildiği, ardından Fransa, İngiltere ve Japonya gibi ülkeler tarafından çeviri araştırmalarının ilerleme gösterdiği görülmektedir. 1950’lerin sonuna doğru ise makine çevirisinin geliştirilmesi hakkında oldukça yüksek bir ilgi olmasına rağmen ilerlemeler aynı doğrultuda hız kazanamamıştır. Çeviri teknolojilerinin 1950-60'l1 y1llarda bu denli gelişebileceğini tahmin etmek belki de güçtü. Bugün çeviri teknolojileri adına gelinen noktadan bakıldığında, gelecekte yapılması muhtemel çalışmalar ve araştırmalar açısından araştırmacılara 1 şı tutar nitelikte yaklaşımlar olduğunu gözler önüne serilmektedir. Çeviri teknolojisi ya da çeviri odaklı teknolojiler denildiğindeyse ilk akla gelenler dijital sözlükler ve ardından makine çevirisi programları ve yazılımlarıdır elbette.

Uzun y1llardır bilindiği ve tecrübe edildiği üzere, Türkiye'nin jeopolitik konumu gereği farklı pek çok ülke ile askeri, siyasi, sağlık, eğitim, edebiyat gibi farklı alanlarda çeviriye ihtiyacı olmuştur. Bu ihtiyacın en kısa sürede hızlı, doğru ve en etkili şekilde karşılanması içinse teknolojinin nimetlerinden faydalanmak kaçınılmazdır. Peki, teknoloji ürünlerini büyük bir hızla kazandığımız ve kullandığımız ürünlerin, yazılımların ve programların isimlerini ne kadar Türkçeleştirebiliyoruz, Türkçeleştirebiliyor muyuz, buna gerek duyuyor muyuz? Araştırma kapsamında ele alınan ve yer yer post-editör adıyla anılan yazılım programları makine çevirisi sistemleri içinde bütünleşik bir şekilde bulunmakla beraber, bu sistemlerden bağımsız olarak da kullanılabilmektedir. Araştırma kapsamında bu programların Türkçe çeviribilim alanında henüz ortak bir şekilde isimlendirilemediği temel alınarak, son-biçimleyici önerisi yapılmaktadır. Bu programlar Türkçe'den erek dile, sıklıkla İngilizce'ye, yapılan çevirilerden sonra ya da çeviri yapmadan doğrudan erek dilde hazırlanan metinler üzerinde yazım, imla hatalarını bulmaya yaramaktadır. Bu özelliklerinin yanı sıra, bazı sonbiçimleyici programlarda anlamsal düzeltmeler, özel kullanımlar, bağlaç, edat kullanımı, büyükküçük harf kullanımı gibi pek çok kullanımın düzeltmesini yapabilmektedirler (Can ve Türkmen, 2018). Bu bağlamda, mevcut araştırmanın amacı çeviri odaklı teknoloji ürünleri sınıflandırmasında yıllardır yerini alan ve çeviribilim araştırmacıları, çevirmenler, çeviri eğitimi alan öğrenciler tarafından aktif bir şekilde kullanılan düzelti aracı olan post-editörlerin Türkçe terim karşılığı için öneride bulunmaktır. 


\section{Yöntem ve Araştırma Soruları}

Mevcut araştırma kapsamında gerekli literatür taraması yapılmıştır. Yürütülen literatür araştırması süresince özellikle çeviri teknolojisi kapsamında Türkçe yayınlanan makalelerde ve akademik çalışmalarda İngilizce karşılığı “post-editor” olan araçların Türkçe’ye nasıl aktarıldığı, ne gibi karşıllklar verildiği incelenmiştir. Bu çalışma esnasında Türkiye'de yer alan ve aktif bir şekilde çeviri hizmeti veren çeviri bürolarının resmî web sitelerindeki post-editor kavramının kullanımı da dikkate alınmıştır. Betimsel analiz kapsamında, araştırmada elde edilen veriler önceden belirlenen temalar veya araştırma soruları doğrultusunda yorumlanmaktadır. Bahse konu verilerin yorumlanmasıyla yapılan betimlemeler neden-sonuç ilişkisi çerçevesinde ve ilgili sonuçlara varma yolunda açıklanmaktadır (Yıldırım ve Şimşek, 2006: 224). Literatür araştırması sonucunda elde edilen veriler bir araya getirilerek karşılaştırılmış ve mevcut araştırma kapsamında betimleyici analiz yöntemi aracılığıyla analiz edilerek değerlendirilmiştir. $\mathrm{Bu}$ sayede araştırmada sunulan sonbiçimleyici kavramının çeviribilim terimleri arasında yer alması için bir nevi durum analizi yapılmış ve öneride bulunulmuştur. Araştırma soruları aşağıdaki şekildedir:

Türkçe Çeviribilim kaynaklarında ve araştırmalarında post-editor kavramı nasıl yer almaktadır?

Bir dil için terimler neden önemlidir?

Post-editor ve ilgili diğer sözcükler için Türkçe terim karşılı̆̆ önerileri nelerdir?

\section{Literatür}

Hız kesmeden her geçen gün gelişmeye devam eden çeviribilimin farklı pek çok disiplinle etkileşim halinde olması gerekçesiyle yeni kavramların ve terimlerin kabulüne ve kullanımına açık bir bilim dalı olduğu aşikârdır. Önemli olan ise toplumumuzun yeni kazandığı kavram ve/veya nesnelerin Türkçe'de nasıl karşılık bulduğudur. Bugün kullandığımız çoğu teknolojik cihazların, programların, yazılımların hatta mobil uygulamanın yerelleştirmesi yapılırken Türkçe bir isim karşılığı bulunmadan, hangi dilden aktarımı yapılıyorsa o dildeki sözcük karşılığıyla kullanıldığı görülmektedir. Bu tür sözcük kullanımları elbette belli bir bilimsel çerçeve sınırında yapılmaktadır.

TDK çevrimiçi sözlükte yer alan en temel anlamlarıyla, terim: (isim) Bir bilim, sanat, meslek dalıyla veya bir konu ile ilgili özel ve belirli bir kavramı karşılayan kelime, 1stılah şeklinde karş1lıklara sahip olduğu görülmektedir. Yine terim kelimesinden türetilen terminoloji: 1. İsimterimler dizgesi, 2. Terim bilimi şeklinde tanımlanmaktadır (TDK Çevrimiçi Sözlük). Pek çok uzman terimlerin tanımlanma yöntemlerini faklı şekillerde sınıflandırır. Mc.Crimon (1984: 183-186), tanımların üç tip olarak sınıflandırılabileceğini belirtmektedir: kısa, koşullu veya geliştirilmiş. Mc.Crimon (1984: 184) genişletilmiş tanımların hem kısa hem de koşullu tanımları içerebileceğini, ancak her ikisinin de ötesine geçtiklerini açıklamaktadır. Esasen, yazarın konuya bakışını açılamaya çalışan, kısa bir tanımda etkili bir şekilde yapılamayan denemelerdir. Genişletilmiş bir tanım sözlük tanımı ile başlayabilir, ancak bu tanıma ekleme, değiştirme ve açıklama eklenebilir. Bunu yaparken, bir anlamı diğeriyle karşılaştırabilir ya da kıyaslayabilir; konuyu hangi sınıfa ait olduğunu ve alt sınıflarının ne olduğunu göstererek sınıflandırabilir; açıklayıcı örneklerle destekleyebilir; konuyu bir süreç olarak ele alabilir (Nirwanto, 2015: 88). Terimlerin genel özellikleri Zülfikar tarafindan şu şekilde sınıflandırıldığ görülmektedir (Zülfikar, 1991: 20-21):

Terimler, bir bilimsel kavrama tek karşılığı bulunan kelimelerdir.

Terimlerin anlamları sabittir ve cümle içinde de olsa değişik anlamlarda kullanılamazlar. Terimlerin bildirdiği anlam yoruma açık değildir ve karşıladıkları kavramı net, açık ve kesin bir biçimde bildirirler.

Terimler halkın söz varlığında yer almazlar ama halk ağzında kullanılıp da sonradan terim özelliği kazanmış, kelimeler vardır. 
Diğer bir yandan, Sağlam terimlerin en belirgin özelliklerini, uluslararası özelliğe sahip, sistematik bir düşüncenin ürünü, ilgili alan diline özgü, bilimsel kavram için tek karşıllı̆g olan, anlamları sınırlı ve sabit, açık seçik ve ölçünlü şeklinde tasnif etmektedir (Sağlam, 2007: 170). Terimler hakkında varılan genel kanılar doğrultusunda, aslında sözcüklerin nasıl terim sınıfına girdikleri, ne gibi özellikler taşıdıkları vurgulanmaktadır. Bu bağlamda, terimlerin bağlı oldukları dillerin zenginliğini de gösterdiğini söylemek yanlış olmayacaktır. Pilav'ın da vurguladığı gibi terimler her bir milletin kültürel mirası ve medeniyetinin geliştirilerek bir sonraki nesle aktarılmasında oldukça önemli rollere sahiptirler. Bu yüzden ülkelerdeki bilim dallarının kendi terim birliklerinin olması gerektiğini, farklı kültürlerden aynen aktarılan terimlerinse o dilin gelişimini engelleyeceğini vurgulamaktadır (Pilav, 2008: 274). Aynı düzlemde ilerlendiğinde, Bican ve Sinan farklı bilim disiplinlerinde aynı terim için birden fazla karşılık kullanılmasının, dilimizin kendi imkânları içinde gelişmesini, terminolojisinin zenginleşmesini ve bilim dili olarak işlemesini olumsuz yönde etkilediğini savunmaktadırlar (Bican ve Sinan, 2018: 760).

Dizdaroğlu çalışmasında, terimlerin bir dilin kültür ve medeniyet dili olarak gelişmişliğinin temel göstergelerinden birisi olduğunu belirtirken, terimlerin, insan beyninin en yüce ürünleri olduğunu ve terimler olmazsa uygarlık ve kültürün bir arpa boyu yol alamayacağını vurgulamaktadır (Dizdaroğlu, 1962:133). Ülkelerde gelişmekte olan bilim dallarının kendi dillerine ait terim ve terminolojilerinin olması gerektiğini savunan ve bu konuda Pilav'a paralel düşüncelerde olan Berk, bahse konu olan bilim dallarının üyeleri tarafindan kabul gören terimlerin ortak bir genellik kazanması ile yüksek bir anlatım düzeyine ulaşacağını vurgulamaktadır. Berk, farklı kaynaklardan ve dillerden alınan yeni terimlerin Türkçe kavram yerleşinceye kadar sınandığını, dolayısıyla da uzun süre yabancı terimlerle birlikte varlıklarını sürdürdüklerini belirtmektedir. Türkçe bilim dilinin, Türkçe sözcüklerle kurulması gerektiğini savunmaktadır (Berk, 2005: 75-77). Özcan Başkan ise Türkçe bilim dilindeki terimlerin Türkçe olmasının yararlarını ve avantajlarını şu şekilde vurgulamaktadır: tanımada yardım, bellemede ve anımsamada kolaylık, bağlantılamada saydamlık, terimlerin özleşmesinde kavram zenginliği ve düşünüm saydamlığı (Başkan, 1974: 179).

Terminolojinin farklı disiplinlerin gelişmesi dolayısıyla kültürler arası aktarım yoluyla kazanıldığ 1 göz önünde bulundurulduğunda, terminoloji ve çeviriyi karşılaştıran Antony Pym'e göre çeviri, bir probleme birden fazla uygulanabilir çözüm arasında seçim yapma yükümlülüğünü içerirken, terminoloji sadece tek bir uygulanabilir çözümün bulunduğu durumları arar. (Pym, Antony, 2011: 93). Çeviri aşamasında ortaya çıkan terminolojik sorunları çözmek için, bir eşdeğer aranırken ya da en uygun eşdeğer seçilirken çevirmenler üç ana kaynak türünü kullanır (Cabre, 2010: 361):

Tek dilli metinsel dokümantasyon kaynakları: konuyla ilgili, tercihen dijital formatta, genellikle internet üzerinden özel metinler.

Terminolojik dokümantasyon kaynakları: iki dilli ve çok dilli sözlükler, terminoloji ve bilgi veri tabanları.

İki dilli veya çok dilli metin kaynakları: paralel veya çok dilli karşılaştırılabilir bütünce (korpus).

Terimlerin günlük dilin bileşenleri olarak kullanılmasının yanı sıra, mesleklerinin doğası gereği terimlerle daha sık veya günlük temas halinde olanların hala bir döngüsü olduğunu vurgulayan Silika, bahse konu döngüyü aşağıdaki şekilde sınıflandırmaktadır:

İdeal terimlerin sahip olması gereken özellikler hakkında meta-teori(üst-kuram) öneren terminoloji teorisyenleri,

terminoloji alanında, somut alan uzmanları tarafından önerilen terimleri (örneğin, çevre koruma, bilgisayar teknolojisi, havacılık, tıp, vb.) değerlendirmek ve onaylamak üzere atanan uzman araştırmacılar, 
yeni terimler oluşturan ve terminoloji teorisi kurallarına uyması gereken profesyonel terminologlar, tercümanlar,

terminologlar tarafından önerilen terimleri kullanması beklenen çevirmenler ve somut ve sabit bir alanında çalışan uzmanlar (Silika, 2020: 125).

İncelenen araştırmalar, terim ve terminoloji oluşturma hakkında verilen öneriler, bir dile ait terimlerin olmasının gerekleri göz önünde tutulduğunda çeviribilim araştırmacılarının, dilbilimcilerin, çevirmenlerin üzerine düşense kendi dillerine katkı sağlamak ve o dili geliştirmek amacıyla hizmet etmektir elbette. Gelişen teknoloji, disiplinler arası ilişkiler, farklı amaçlar doğrultusunda yürütülen uluslararası ilişkilerin sürecinde çeviriye ihtiyaç olduğu aşikârdır. Çeviri sürecinde ise erek dile aktarılan ve kazandırılan yeni sözcükler ve dolayısıyla terimler ortaya çıkmaktadır. Bu bağlamda, Mona Baker'ın çeviri stratejileri sınıflandırmasında yer alan kültürel ikame (yerine koyma), ilgili sözcükle aktarım (yorumlama) gibi stratejiler terim oluşturmada kullanılmaktadır (Baker, 1992: 40-45). Yalçın'ın Dickens'tan aktardığına göre, erek metinden hareketle çeviri sürecinde yabancı olanı vermektense özgün eserin yazarının ve çevirmenin erek dilde yazacağı şekilde yazarak kültür nakli yapması dolayısıyla yerlileştirme yapması terim oluşturma konusunda kullanılan stratejilerden birisi olarak kabul edilebilmektedir (Yalçın, 2015: 104; Dickens, 2002: 32). Diğer bir taraftan Mine Yazıcı'nın da belirttiği gibi bazı durumlarda yeniden yazım olarak da değerlendirdiği uyarlama yoluyla çeviri ve erek kültürden hareketle yeni sözcük türetme, sözcügün tamlama ya da eşdizimli sözcüklerin anlamından yola çıkarak çıkarımda bulunma (Yazıcı, 2007: 32-36) ile terimler olușturulabilmektedir. Özellikle erek dilde terim olușturma ve yeni sözcük kazanımı konusunda etkili olabilecek bahse konu stratejiler diller arası çeviri sürecinde kullanılan stratejiler olarak kabul edilmektedir. Mevcut çalışma kapsamında ise yürütülen literatür incelemesi sonucunda İngilizce kullanımı post-editor olan sözcügün Türkçe kaynaklarda yer yer aynen kullanıldığı ya da makine çevirisi sonrası düzeltme şeklinde açımlama/açıklama yöntemiyle karşılık verildiği görülmüsstür. Dolayısıyla çalışmanın amacı olan son-biçimleyici sözcüğü ve bununla ilişkili diğer sözcük ve kullanımların önerisi yapılmadan önce ulaşılan Türkçe kaynaklardaki kullanımlar sonuç ve öneriler kısmında verilmiş, ardından öneri sözcük ve kullanımlar verilmiştir.

\section{Sonuç}

Araştırma kapsamında yürütülen literatür taramasında post-edit ya da post-editing kavramının çeviribilimle bağlantılı bir şekilde incelendiği Türkçe makaleler ve kitaplar taranmıştır. Mevcut araştırmanın araştırma soruları ile bağlantılı bir şekilde değerlendirme ve elde edilen sonuçlara değinmek gereklidir. İlk araştırma sorusu, "Türkçe Çeviribilim kaynaklarında ve araştırmalarında post-editor kavramı nasıl yer almaktadır?”. Bu soruya cevaben, araştırma kapsamında, çevirmenler/tercümanlar tarafından makine çevirisine bağlı ya da makine çevirisinden bağımsız şekilde kullanılan bu programlara Türkçe araştırmalarda pek yer verilmediği gözlemlenmiştir. Sıklıkla yabancı dilde yürütülen, makine çevirisi ve/veya çeviri odaklı teknoloji konulu, araştırmalarda son-biçimleyici programlarının detaylı bir şekilde incelendiği görülmüştür. Diğer araştırma sorusu, "Post-editor ve ilgili diğer sözcükler için Türkçe terim karşıllğı önerileri nelerdir?" şeklindedir. Bu sorulara cevaben, profesyonel çeviri bürolarının web siteleri ve blog sayfaları incelendiğinde bu kavramın makine çevirisi sonrası düzelti/düzeltmenlik şeklinde verildiği görülmektedir. Türkçe araştırmalarda yer alan bazı kullanımlar şu şekildedir: bilgisayar çevirisini düzeltme (Şahin, 2015), son-düzeltme (Balkul, 2015), son-biçimleyici (Can ve Türkmen, 2018), sonbiçimleme (Türkmen, 2019), makine çevirisi sonrası düzeltme (Çetiner, 2019). Mevcut araştırma kapsamında literatürde ve pratikte post-editör ya da makine çevirisi sonrası düzelti/düzeltme gibi karşılıklarla kullanılan son-biçimleme kavramı için Türkçe çeviribilim araştırmalarında terminoloji birliği adına katkı sağlayacağı düşünülen öneriler aşağıdaki şekilde verilmiştir:

post-edit: (fiil) son-biçimleme yapmak 
post-editing: (isim) son-biçimleme

post-editor: (isim) son-biçimleyen/ son-biçimleyici. Son-biçimleme işini yapan kişi ve son-biçimleme programları/uygulamaları.

Araştırma kapsamında sorulan bir diğer araştırma sorusu ise "Bir dil için terimler neden önemlidir?" şeklindedir. Yürütülen literatür araştırmasıyla bağlantılı olarak, terimlerin bir dil için gerekliliği kısaca şu şekilde özetlenebilir: ait oldukları dilin zenginliğini göstermesi, tutarlı ve bağdaşık olmasını ve dilin kendi içinde birliğini sağlaması, dolayısıyla bilimselliğinin göstergesi olması. Son-biçimleyicilerin sadece makine çevirisinden sonra kullanılmadığı, erek dilde kaliteli ve düzgün bir metin oluşturabilmek için, hazırlanan metinlerin yazım denetimini, imla, noktalama, doğru sözcük, edat, bağlaç vb. kullanımını destekleyen programlar olduğu, makine çevirisi yazılım ve programlarına bütünleşmiş ya da bağımsız şekilde kullanıldıkları göz ardı edilmemelidir. Bu bağlamda son-biçimleyiciler sadece makine çevirisi ile bağlantılı olarak düşünülmemeli, kaliteli metin üretiminde editörlere, yayınevlerine, içerik hazırlayanlara, çevirmenlere, öğrencilere, araştırmacılara fayda sağlayan yazılımlar olduğu için isminin son-biçimleyici olarak kullanılması önerilmektedir. Son-biçimleyicilerle ilgili ileri dönemde yürütülecek çalışmalar kapsamında, çeviri kalitesi başlığı altında makine çevirilerinin son-biçimleyici özelliklerini kıyaslayan çalışmalar yapılabilir. Farklı bağımsız son-biçimleyicilerde aynı metni nasıl düzelttiğine dair kıyaslamalı bir çalışma yapılabilir. Sadece yazım denetimi yapan programlar (spellchecker) ve bağımsız sonbiçimleyiciler üzerinde aynı metni denetleyerek kıyaslamalı çalışmalar yapılabilir. Ayrıca, farklı metin türleriyle tek bir son-biçimleyicinin metin kalitesi hakkında veriler elde edilebilecek kıyaslamalı çalışmaların yapılması önerilmektedir.

\section{Kaynakça}

Baker, M. (1992). In Other Words, Routledge.

Balkul, H. İ. (2015). Türkiye'de Akademik Çeviri Eğitiminde Çeviri Teknolojilerinin Yerinin Sorgulanması: Müfredat Analizi ve Ögrretim Elemanlarının Konuya İlişkin Görüşleri Üzerinden Bir İnceleme, Doktora Tezi, Sakarya Üniversitesi.

Başkan, Ö. (1974). Terimlerde Özleşme Sorunu, Türk Dili Araştırmaları Yıllı̆̆ı: Belleten, TDK Yayınlar1.

Berk, Ö. (2005). Kuramlar Işı̆̆ı̆da Açıklamalı Çeviribilim Terimcesi, Multilingual.

Bican, G.; Sinan, A.T. (2018). Türkçe Öğretiminde Kullanılan Terim Sözlüklerinin Karşılaştırılması, Uluslararas1 Türkçe Edebiyat Kültür Eğitim Dergisi, 7(2), $759-770$. https://dergipark.org.tr/tr/pub/teke/issue/38234/442039

Cabre, M. Teresa, (2010). Terminology and Translation, John Benjamins Publishing Company.

Can, M. Z.; Türkmen, B. (2018). Yabancı Dile Doğru Gerçekleştirilen Çevirilerde Bağımsız Son Biçimleyicilerin İşlevleri: Çeviribilim Öğrencileriyle Gerçekleştirilen Bir Uygulama Örneği, International Journal of Language Academy, ISSN: 2342- 0251. http://dx.doi.org/10.18033/ijla.4026

Çetiner, C. (2019), Makine Çevirisi Sonrası Düzeltme İşlemine (Post-editing) Yönelik Kapsamlı Bir İnceleme, RumeliDE Journal of Language and Literature Studies, 2019 Kasım, s. 462-472. DOI. 10.29000/rumelide.649333

Dickens, J.; Hervey, S.; Higgins, I. (2002). Thinking Arabic Translation, A Course in Translation Method: Arabic to English, Routledge.

Dizdaroğlu, H. (1962). Terimler Üzerine, Türk Dili, 133, 35-37. 
Mc. Crimon, J.M. (1984). Writing With a Purpose, Houghton Mifflin Company.

Nirwanto, R. (2015). The Methods of Defining Terms Found in Theses of the EFL Students, Journal on English as a Foreign Language, 5(2), 87-98.

Pilav, S. (2008). Terim Sorunu ve Eğitim Ö̆̆retimde Terimlerin Yeri ve Önemi, Kastamonu Eğitim Dergisi, 16(1), 267-276.

Pym, A. (2011). Translation Research Terms: A Tentative Glossary For Moments of Perplexity and Dispute, From Translation Research Projects 3, Ed. Anthony Pym, Intercultural Studies Group, 75-110.

Sağlam, M.Y. (2007). Türkçedeki Terim Sorunsal, Türkbilig, 2007/14, 168-176.

Silıs, J. (2010). Developing Latvian Terminology of Translation Studies: The First Steps, Vertimo Studijos, 3,

Şahin, M. (2015). Çevirmen Adaylarının Gözünden Ingilizce Türkçe Bilgisayar Çevirisi ve Bilgisayar Destekli Çeviri: Google Deneyi, Çeviribilim ve Uygulamaları Dergisi, 21, 43-60.

TDK çevrimiçi sözlük: https://sozluk.gov.tr/, Erişim tarihi: 24.04.2020.

Türkmen, B. (2019). Çeviri Eğitiminde Teknoloji ve Dijital Medya Edinci, Gece Akademi.

Yazıcı, M. (2007). Yazılı Çeviri Edinci, Multilingual.

Yalçın, P. (2015). Çeviri Stratejileri Kuram ve Uygulama, Grafiker Yayınları.

Yıldırım, A. ve Şimşek, H. (2006). Sosyal Bilimlerde Nitel Araştırma Yöntemleri (6. Basım), Seçkin Yayınc1lik.

Zülfikar, H. (1991). Terim Sorunları ve Terim Yapma Yolları, TDK Yayınları. 